\title{
Determination on Genetic Variation for Morphological Traits and Yield Components of New Winter Wheat (Triticum aestivum L.) Lines
}

\author{
Sali ALIU, Shukri FETAHU \\ University of Prishtina, Faculty of Agriculture, 10000 "Bill Clinton” Str., Prishtina, Albania; s_aliu@hotmail.com
}

\begin{abstract}
The genetic studies were conducted on six new winter wheat (Triticum aestivum L.) line during three years investigations developed in agro ecological conditions of Kosovo. Data for various morphological and yield traits were taken and analyzed for spike length (SL), plant height $(\mathrm{PH})$, total dry matter (TDM), spike Weight (SW), grain weight per spike (GWS), yield (Y) and harvest index (HI). Field design consisted in a randomized blocks design (RBD) with three replications. Results indicated that the line $01 \mathrm{KS}$ as the most competitive genotypes produced significantly higher for SL $(9.58 \mathrm{~cm})$, GWS $\left(2.37\right.$ g per spike) and grain yield $\left(10.66 \mathrm{t} \mathrm{ha}^{-1}\right)$ while lower yield was recorded at the line $04 \mathrm{KS}\left(8.02 \mathrm{t} \mathrm{ha}^{-1}\right)$. The lowest $\mathrm{SL}(8.4 \mathrm{~cm})$ belonged to line $06 \mathrm{KS}$ which was ranked as the least competitive genotype. The significantly higher total dry matter (TDM) was recorded at the wheat line $02 \mathrm{KS}$ on value $4.88 \mathrm{~g}$, while the lowest (4.44 g) belonged to $04 \mathrm{KS}$ which was ranked as the last genotype. There was a positive and significant harvest index (HI) on value from $50.5 \%$ to $39.1 \%$.
\end{abstract}

Keywords: wheat line, genotypes, spike length, total dry matter, harvest index, yield

\section{Introduction}

Common wheat (Triticum aestivum L.) is an important cereal crop of Kosovo and a major component of bread. Based on area and production it ranks first in cereals. Statistics of Kosovo (2008-2009) winter wheat was grown on a total area of $60.000-70.000 \mathrm{ha}^{-1}$ on total production of 214.500 thousand tones with average yield 3.3 $\mathrm{t} \mathrm{ha}^{-1}$, according to the data of MAFRD (2009), whereas needs for wheat seed per year in are about 10.000-12.000 tones of $\mathrm{C}_{2}$ certificated seed. During the last few decades, better progress has been made in increasing the unit area yield of wheat in the country. By comparing the yield of wheat per unit area of Kosovo with the per unit area yield of wheat of the advanced countries, we are still outlying at the rear. Wheat is a staple diet and provides more nourishment for the people of the world than any crop. About $90 \%$ of the world's wheat production consist of the three species; Triticum aestivum L. (common wheat), Triticum compactum (club wheat) and Triticum durum (durum or macaroni wheat) cited by Mahmood et al. (2006). The objective of plant breeding is the development of cultivars combining high and stable and productivity with good quality (Fasoula, 2008). A great success of developing high yielding wheat genotypes has been achieved through breeding. Improvement of grain quality is a major objective of most breeding programs. Recently scientist associated the progress in plant breeding with the presence of diverse source material with new germplasm, including such created by breeders as published by Mangova and Rachovska (2004).
Yield is the complex traits and is a result of value of yield components as well; plant height, number of spikltes per spike, number of grain per spike, grain weight per spike and other parameters and it's influenced by genotype and agro ecological conditions by Drezner et al. (2007). Several morphological parameters such as plant height, grain yield have been indentified to many researches (Ahmed et al., 2007; Garol et al., 2005). The global climatic changes and the increase of the population lead to increasingly stronger emphasis on productivity as well as on the end use quality traits of the new wheat varieties as published by Atanasova et al. (2008). Several institutions create and improve new cultivars, in order to achieve higher production, and demands of the population (Vural et al., 2007). Common wheat (Triticum aestivum L.) provides the nutrition for the greater part of the world population. The objective of this paper was to determine variations between examined winter wheat lines genotypes using morphological data (plant height, spike length, grain weight per spike, harvest index) and yield for three years' investigations. This information will be useful to improve the developed wheat lines.

\section{Materials and methods}

\section{Experimental site}

The experiment was conducted in Prishtina region which is located in the Kosovo agro ecological region on elevation $570 \mathrm{~m}$. Plants were grown during growing seasons 2005-2006 (Y1), 2006-2007 (Y2) and 2008-2009 (Y3). This region is the $5 \mathrm{~km}$ southwest part of capital city 
122

Prishtina, with receiving variable rainfall averaging about $613.3 \mathrm{~mm}$ per year. The region has mean annual temperature of about $10.27^{\circ} \mathrm{C}$. Summer temperatures in these region sometimes reach more $35^{\circ} \mathrm{C}$ resulting to high evapo transpiration.

\section{Plant material and experimental design}

The experiments were conducted as a randomized complete block design (RCBD) with three replicates Genotypes (Line) (6) x Years (3) x Repetitions (3) x locality (1) $\mathrm{x}$ parameters $(6)=324$ combination. Plant materials used in this study were six new winter wheat lines coded as: $01 \mathrm{KS}, 02 \mathrm{KS}, 03 \mathrm{KS}, 04 \mathrm{KS}, 06 \mathrm{KS}$, and $07 \mathrm{KS}$, originating from the Faculty of Agriculture in Prishtina. The plot sizes were $15 \mathrm{~m}^{2}$, while plot seeds were sown was 450 seed $\mathrm{m}^{-2}$. The experimental population received normal agronomic and plant protection care, except irrigation.

\section{Measurements}

Under the growing conditions of these experiments to determine morphological data per plant; plant height $(\mathrm{PH})$; of the main tiller at maturity was measured in centimetres from base of the stem up to the apex. Spike length (SL) of the main spike o selected plant excluding awn was measured at the maturity in centimetres. Total dry matter (TDM) was measured at maturity together stem from base up to the apex (spike) in grams per plant. Spike weight was measured from the plants at maturity in grams, while yield was calculated in $\mathrm{t} \mathrm{ha}{ }^{-1}$. Regarding to grain weight per spike (GWS) at maturity all the randomly selected plants were harvested manually, threshed on machine separately and their recoded in grams. Harvest Index (HI), were calculated on percentage basis in each plot using the following formulae:

Harvest Index,

$$
(\mathrm{HI})=\frac{G y}{B y} \times 100^{\text {were }}
$$

Gy- represent grain yield and By- is Biological yield.

We measured at field and laboratory plants were randomly harvested from plots; 5 plants per repetition $\mathrm{x} 3$ repetition $\mathrm{x} 6$ wheat line $\mathrm{x} 6$ parameters $=540$ plants.

\section{Statistical analysis}

The data for all the trials were analyzed by analysis of variance (ANOVA). Differences for means of various characters were computed using least significance differ- ences test (LSD) at 0.05 and 0.01 level of probability. The computer software MINITAB-14 was used for these computations. Relationships among the traits were estimated by Pearson correlation analysis. Mean values of the agronomic traits for wheat genotypes were standardized and used for computing Euclidean distances between them.

\section{Results and discussion}

Mean square for different traits and yield components which are included in our investigations are presented in Tab. 1. All sources of variance were a significant source of spike length, grain weight per spike, yield, and harvest index, while interaction between line $\mathrm{x}$ year also were significantly higher at all investigations traits.

The morphological development of traits wheat is a highly co-ordinated process. During the growing season wheat plants height variation, means, standard deviations, values for various morphological and yield traits in six wheat genotypes lines (Tab. 2). Results for the three years investigations indicated that wheat genotype $02 \mathrm{KS}$ produced significantly higher plant height $(80.6 \mathrm{~cm})$ compared with other genotypes. The lowest plant height belonged to $07 \mathrm{KS}(74.7 \mathrm{~cm})$ wheat genotypes. In comparison to value $\mu(78.20 \mathrm{~cm})$ the difference were $+2.4 \mathrm{~cm}$ (3.06\%) and was associated with reduction in plant height $(4.48 \%)$ or $-3.5 \mathrm{~cm}$ respectively. There was significant increase at $\mathrm{p}=0.05$. The coefficient of variation and standard deviation of plant height of all wheat genotypes lines were $3.01 \%$ and 2.34 respectively. The results regarding phenotypic correlation coefficients are presented in Tab. 3 . The results revealed that phenotypic correlations were on different values. Plant height was positively and significantly correlated with total weight plant $\left(0.80^{* *}\right)$, while negative correlation was recorded with yield $(-0.06)$ and harvest in$\operatorname{dex}(-0.18)$ respectively. In the studies of Mohammad et al. (2006) they obtained different results for plant height at the different wheat genotypes from $62 \mathrm{~cm}$ to $110 \mathrm{~cm}$. The similar results were obtained by Fetahu et al. (2008) they are realized results for plant height from 70.8 to $79.05 \mathrm{~cm}$.

Significantly higher differences were observed in dry matter on different new wheat genotypes lines. The results regarding total dry matter (TDM) of the maximum value was obtained by genotype lines $02 \mathrm{KS}$ ( $4.88 \mathrm{~g}$ per plant) compared with value $\mu$ ( $4.63 \mathrm{~g}$ per plant) that had higher $+0.25 \mathrm{~g}$ or expressed in relative value $5.39 \%$. Wheat line

Tab. 1. Mean square of morphological traits and yield components

\begin{tabular}{cccccccc}
\hline Sources of variation & Plant height & Total dry matter & Spike weight & Spike length & $\begin{array}{c}\text { Grain weight } \\
\text { spike }\end{array}$ & Yield & Harvest index \\
\hline (A) Line & $1.99^{*}$ & $1.56^{\text {N.S }}$ & $2.00^{*}$ & $16.92^{* *}$ & $11.34^{* *}$ & $10.82^{* *}$ & $15.7^{* *}$ \\
(B) Year & $0.68^{\text {N.S }}$ & $77.32^{* *}$ & $50.42^{* *}$ & $115.32^{* *}$ & $148.45^{* *}$ & $22.05^{* *}$ & $12.98^{* *}$ \\
A x B & $1.13^{\text {N.S }}$ & $2.85^{*}$ & 2.013 & $3.54^{* *}$ & $5.1^{* *}$ & $3.4^{* *}$ & $10.32^{* *}$ \\
Error & - & - & - & 0.12 & - & - & - \\
\hline
\end{tabular}

${ }^{*},{ }^{* *}$ is significant at $\mathrm{p}=0.05$ and $\mathrm{p}=0.01$ respectively 
Tab. 2. Means and standard deviation for various related traits in six wheat genotypes lines

\begin{tabular}{|c|c|c|c|c|c|c|c|c|c|c|c|c|c|c|}
\hline \multirow[t]{3}{*}{ Lines } & \multirow{2}{*}{$\begin{array}{c}\mathrm{PH} \\
(\mathrm{cm})\end{array}$} & & \multicolumn{2}{|c|}{ TDM } & \multicolumn{2}{|c|}{ SW } & \multicolumn{2}{|c|}{ SL } & \multicolumn{2}{|c|}{ GWS } & \multirow{2}{*}{$\begin{array}{c}\mathrm{Y} \\
\mathrm{t} \mathrm{ha}^{-1}\end{array}$} & \multicolumn{3}{|c|}{$\mathrm{HI}$} \\
\hline & & & $(\mathrm{g})$ & & (g) & & $(\mathrm{cm})$ & & $(\mathrm{g})$ & & & & $\%$ & \\
\hline & Mean & $\pm \mathrm{SD}$ & Mean & $\pm \mathrm{SD}$ & Mean & $\pm \mathrm{SD}$ & Mean & $\pm \mathrm{SD}$ & Mean & $\pm \mathrm{SD}$ & Mean & $\pm \mathrm{SD}$ & Mean & $\pm \mathrm{SD}$ \\
\hline $01 \mathrm{KS}$ & 79.0 & \pm 3.61 & 4.69 & \pm 0.40 & 2.66 & \pm 0.04 & 9.58 & \pm 0.33 & 2.37 & \pm 0.14 & 10.66 & \pm 0.63 & 50.5 & \pm 5.82 \\
\hline $02 \mathrm{KS}$ & 80.6 & \pm 1.84 & 4.88 & \pm 0.16 & 2.49 & \pm 0.12 & 9.57 & \pm 0.41 & 2.01 & \pm 0.16 & 8.96 & \pm 0.68 & 41.1 & \pm 2.09 \\
\hline $03 \mathrm{KS}$ & 79.6 & \pm 2.15 & 4.67 & \pm 0.41 & 2.74 & \pm 0.35 & 9.40 & \pm 0.43 & 2.05 & \pm 0.20 & 9.20 & \pm 0.91 & 43.8 & \pm 2.33 \\
\hline $04 \mathrm{KS}$ & 75.8 & \pm 5.93 & 4.44 & \pm 0.65 & 2.11 & \pm 0.09 & 9.10 & \pm 0.70 & 1.79 & \pm 0.14 & 8.02 & \pm 0.63 & 40.3 & \pm 0.65 \\
\hline 06KS & 79.2 & \pm 3.17 & 4.57 & \pm 0.43 & 2.40 & \pm 0.25 & 8.40 & \pm 0.70 & 1.79 & \pm 0.12 & 8.05 & \pm 0.54 & 39.1 & \pm 1.62 \\
\hline $07 \mathrm{KS}$ & 74.7 & \pm 2.91 & 4.54 & \pm 0.67 & 2.50 & \pm 0.27 & 8.90 & \pm 0.64 & 199 & \pm 0.34 & 10.08 & \pm 0.69 & 43.8 & \pm 2.50 \\
\hline$\mu$ & 78.2 & & 4.63 & & 2.48 & & 9.16 & & 2.00 & & 9.16 & & 43.13 & \\
\hline LSD 0.05 & 8.50 & & 0.67 & & 0.50 & & 0.70 & & 0.37 & & 1.59 & & 4.94 & \\
\hline 0.01 & 12.09 & & 0.95 & & 0.71 & & 0.99 & & 0.53 & & 1.60 & & 7.03 & \\
\hline
\end{tabular}

Notes: PH; Plant Height, TDM; Total dry matter, SW; spike weight, SL; spike length, GWS; grain weight spike, Y; yield, and HI; harvest index

04KS had the lowest TDM (4.44 g), compared by the mean, was associated on reduction $-0.19 \mathrm{~g}$ or $4.10 \%$ respectively. In comparison to value $\mu$ for biological dry matter the significant differences between genotypes $02 \mathrm{KS}$ and $04 \mathrm{KS}$ were +0.44 or $9.50 \%$ respectively. Tab. 3 presents the correlation matrix between TDM and others agronomic characteristics. Differences were observed in the correlation coefficients exhibited positive correlations with grain weight per spike $\left(0.51^{*}\right)$, yield $(0.31)$. However, harvest index exhibited negative correlation coefficients of -0.043 . The coefficient of variation for TDM was 3.30\%. Several reports have studied by the different authors. Almost similar results from 3.87 to $4.85 \mathrm{~g}$ have been earlier reported by Fetahu et al. (2008).

Spike weight is a character of considerable importance in the development of plant and determines the productivity of the plant as published by Rajaram et al. (1996). The results regarding spike weight $(\mathrm{SW})$ have been presented in Tab. 1. The results revealed that the SW were positive and significantly higher on $\mathrm{p}=0.01$ respectively. Genotype

Tab. 3. Phenotypic correlation coefficient among six characters of wheat (Triticum aestivum $\mathrm{L}$ )

\begin{tabular}{lccccc}
\hline \multicolumn{1}{c}{ Characters } & $\begin{array}{c}\text { Spike } \\
\text { Length } \\
\left(\mathrm{X}_{2}\right)\end{array}$ & $\begin{array}{c}\text { Total } \\
\text { dry } \\
\text { matter } \\
\left(\mathrm{X}_{3}\right)\end{array}$ & $\begin{array}{c}\text { Grain } \\
\text { weight } \\
\text { Spike } \\
\left(\mathrm{X}_{4}\right)\end{array}$ & $\begin{array}{c}\text { Yield } \\
\left(\mathrm{X}_{5}\right)\end{array}$ & $\begin{array}{c}\text { Harvest } \\
\text { Index } \\
\left(\mathrm{X}_{6}\right)\end{array}$ \\
\hline $\begin{array}{l}\text { Plant height } \\
(\mathrm{PH})\left(\mathrm{X}_{1}\right)\end{array}$ & 0.37 & $0.80^{* *}$ & 0.30 & -0.06 & -0.18 \\
$\begin{array}{l}\text { Spike length } \\
(\mathrm{SL})\left(\mathrm{X}_{2}\right)\end{array}$ & - & $0.63^{*}$ & $0.70^{*}$ & 0.50 & 0.54 \\
$\begin{array}{l}\text { Total dry matter } \\
(\mathrm{TDM})\left(\mathrm{X}_{3}\right)\end{array}$ & - & - & 0.51 & 0.31 & -0.043 \\
$\begin{array}{l}\text { Grain weight } \\
\text { spike } \\
(\mathrm{GW})\left(\mathrm{X}_{4}\right)\end{array}$ & - & - & - & $0.89^{* *}$ & $0.79^{* *}$ \\
$\begin{array}{l}\text { Yield } \\
(\mathrm{Y})\left(\mathrm{X}_{5}\right)\end{array}$ & - & - & - & - & $0.75^{* *}$ \\
\hline${ }^{*}$,** is significant at $\mathrm{p}=0.05$ and $\mathrm{p}=0.01$ respectively. & & \\
\hline
\end{tabular}

mean of SW per plant ranged between $2.11 \mathrm{~g}$ for wheat line $04 \mathrm{KS}$ and $2.66 \mathrm{~g}$ for wheat line $01 \mathrm{KS}$. In comparison to value $\mu(2.48 \mathrm{~g})$ differences were $-0.37 \mathrm{~g}$ which was reduce of $14.91 \%$ and $+0.18 \mathrm{~g}(7.25 \%)$. The differences among the higher and lowest obtained results were +0.55 g per spike or with total genetic variation $22.17 \%$. Significantly higher correlation coefficients were found for grain weight per spike $\left(0.70^{*}\right)$ and total dry matter $\left(0.63^{*}\right)$ (Tab. 3 ). The spike weight has received considerable attention because grain yield is closely related to the number of grain per spike and to the individual grain size by Hirotake $e t$ al. (1998) which also realised significant results for these traits. The mean spike lengths of six new winter wheat lines were $9.16 \mathrm{~cm}$ (Tab. 2.). Higher value of SL were observed for wheat $01 \mathrm{KS}(9.58 \mathrm{~cm})$, while line $06 \mathrm{KS}$ had the lowest SL $(8.4 \mathrm{~cm})$. In comparison to value $\mu$ differences were $+0.42 \mathrm{~cm}(4.58 \%)$ and wheat line was associated with reduction on $-0.76 \mathrm{~cm}(8.29 \%)$. The genetic variation of spike length was $+1.18 \mathrm{~cm}$ or in relative value $12.88 \%$ respectively. Significantly higher and positive correlation were found between SL and GWS on value $\left(0.70^{*}\right)$. The coefficient of variation for SL during three year investigations is $4.99 \%$. Several reports have been presented for spike length. According to Gorjanovic et al. (2006) the maximum spike length was from 7.69 to $8.14 \mathrm{~cm}$. Analyzed wheat lines expressed differences of grain weight per spike values (Tab. 2). Grain weight or grain productivity per spike has the highest impact in expression of genetic yield potential cited by Knezevic et al. (2008). The values of grain weight per spike ranged from $2.37 \mathrm{~g}$ for wheat line $01 \mathrm{KS}$ to $1.79 \mathrm{~g}$ for line $04 \mathrm{KS}$. Variability expressed by coefficient of variability was $10.64 \%$ relatively wide diversity. The wheat line $01 \mathrm{KS}$ had higher grain weight +0.37 $\mathrm{g}(18.5 \%)$ than value $\mu(2.0 \mathrm{~g})$ and $+0.58 \mathrm{~g}$ than wheat line $04 \mathrm{KS}$. That is expressed on genetic variation $29 \%$. Wheat lines showed positive and significantly higher correlation coefficients of yield $\left(0.89^{* *}\right)$ and harvest index $\left(0.79^{* *}\right)$. Tab. 2 shows assessment of new winter wheat lines according to grain yield. Average grain yields at all geno- 


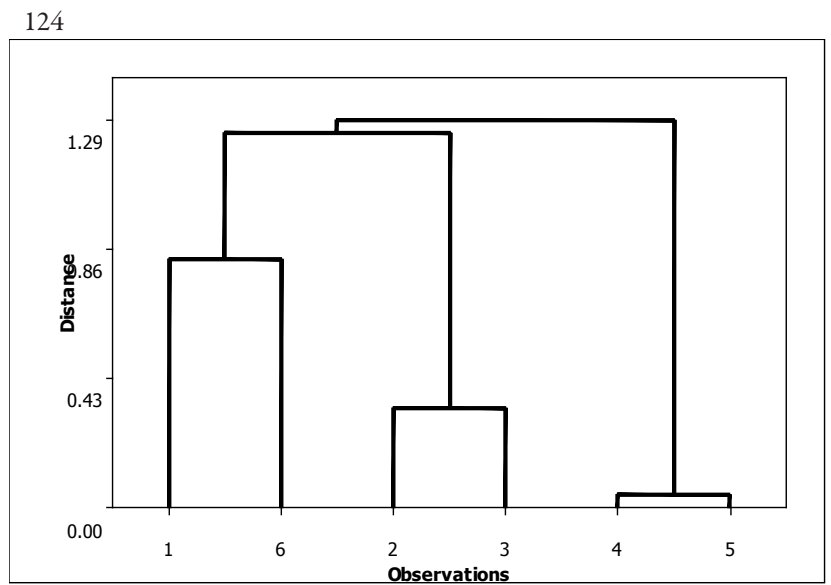

Fig. 1. Dendrogram of analyzed wheat lines developed in Kosovo

types were $9.16 \mathrm{t} \mathrm{ha}^{-1}$ which can guarantee higher yield. There were statistical differences for yield at $p=0.01$. The highest-yielding according to three years' was observed in new wheat line $01 \mathrm{KS}$ on average value $10.66 \mathrm{tha}^{-1}$, which was distinguished by high genetic variability. The lowest yield was realized at wheat line $04 \mathrm{KS}$ on value $8.02 \mathrm{t}$ $\mathrm{ha}^{-1}$. In comparison to value $\mu\left(9.16 \mathrm{tha}^{-1}\right)$ the differences among extreme value were $+1.5 \mathrm{tha}^{-1}(16.37 \%)$ and -1.14 $\mathrm{t} \mathrm{ha}^{-1}(12.44 \%)$ which had genetic variation $28.82 \%$. The significant correlation coefficient were found for yield and harvest index $\left(0.75^{*}\right)$. Phenotypic distance and similarity of studied genotypes were computed by cluster analysis. By analysis of dendrogram we can find three groups of wheat genotypes. Each group consist two genotypes. The most similar genotypes are first group (04KS and 06KS). The second group most similar belonged wheat genotypes $02 \mathrm{KS}$ and $03 \mathrm{KS}$. Third group there are also two wheat genotypes $01 \mathrm{KS}$ and $07 \mathrm{KS}$, expressed the highest distance in relation to other wheat genotypes (Fig.1).

Data collected along with their statistical analyses are presented in Tab. 2. It is clear from analysis of variance an average harvest index value varied from 39.1 to $50.5 \%$. The differences between new wheat lines genotypes $(01 \mathrm{KS}$ and $06 \mathrm{KS}$ ) were $+11.4 \%$. The average value of harvest index at all wheat lines was $3.13 \%$ which was manifested on genetic variation $26.43 \%$. Several authors have reported different results for harvest index. Herthmuth et al. (1995) realised harvest index from 0.39 to 0.52 .

\section{Conclusions}

Results of our research indicated significantly different between new wheat lines for morphological and yield components. The investigation suggests that the new wheat lines based in our study represent a highly genetic valuable for spike length, spike weight, grain yield and harvest index and this material could be successively used in production for different purpose because, have a good perspective in seed production after evaluated for VCU and DUS- test.

\section{References}

Aliu, S., Sh. Fetahu, A. Salillari and L. Rozman (2007). The inheritance of yield and yield components of five wheat hybrid under drought conditions. Journal Agri. Science. $8(2): 53-59$.

Atanasova, D., N. Tsenov, I. Stoeva and V. Dochev (2008). Genotype x environment interaction for some quality traits of Bulgarian winter wheat variety. Modern variety breeding for present and future needs, Valencia, Spain. 532-537.

Drezner, G., K. Dvojkovic, D. Horvat, D. Novoselovic and A. Lalic (2007). Environmental impacts on wheat agronomics quality traits. Cereals Res. 35:357-360.

Fasoulas, V. (2008). Two novel whole-plant field phenotyping equations maximize selection efficiency. Modern variety breeding for present and future needs. Valencia, Spain. 361365 .

Fetahu, S. H., S. Aliu, S. Kaciu, I. Rusinvoci and M. Gjonbalaj (2008). Characteristics of production potential for yield and biomass of new winter wheat line developed in Kosovo. Modern variety breeding for present and future needs. Valencia, Spain. 367-371.

Goral, H., M. Tyrka and L. Spiss (2005). Assessing genetic variation to predict the breeding value of winter triticale cultivars and lines. J. Appl. Genetics. 46(2):125-131.

Gorjanovic, B., and M. Balalic (2006). Correlations among yield components in durum wheat. Genetika. 38(2):115-120.

Hirotaki, I., U. Kichachiu and Y. Kooy (1998). Analysis of spike development of three spring wheat genotypes under various cultural condnoitis. Plant Prod. Sci. 1(4):258-263.

Hremuth, D., J. Stehno, V. Dvoracek and L. Leisova (1995). Winter wheat landraces and obsolete cultivars-possible donors of characters for breeding. Crop Research. 387-391.

Knezevic, D., V. Zecevic, D. Dodig (2008). Genetic and phenotypic variability of grain mass per spike of winter wheat genotypes. Kragujevac J. Sci. 30:131-136.

Mahmood, Q., Wu Dong., S. Afsari, R. Muhamed and J. Ghulam (2006). Heterosis, correlation and path analysis of morphological and biochemical characters in wheat (Triticum aestivum ). Agriculture Journal. 1(3):180-185.

Mangova M., G. Raohvska (2004). Technological characteristics of newly developed mutant common winter wheat lines, Plant Soil Environment. 50(2):84-87.

Mohamed, A., Z. Eskander and S. Saeid (2006). Iranian winter wheat interference with weeds. Pak. Jour. Weed. Sci. Res. 12(3):131-144.

Rajaram, S., H. Braun and M. Ginkel (1996). CIMMYT's approach to breed of drought tolerance. Euphytica. 92:147153.

Vural, H. and A. Karasu (2007). Agronomical characteristics of several chickpea ecotypes (Cicer arientum) grown in Turkey. Notulae Botanicae Horti Agrobotanici Cluj-Napoca. $35(2): 33-38$. 